\title{
Evaluation of different drying processes by energy consumption in an insulated and not insulated laboratory convection dryer
}

\author{
*Maysami, M.A., Sedighi, R. and Ghaffari, H. \\ Biosystems Engineering Department, Faculty of Agriculture, University of Tabriz, $29^{\text {th }}$ Bahman Avenue, \\ 5166616471 Tabriz, Iran
}

\section{Article history:}

Received: 11 May 2020

Received in revised form: 27

June 2020

Accepted: 4 October 2020

Available Online: 27

December 2020

Keywords:

Apple,

Drying,

Energy consumption,

Insulation,

Time duration

DOI:

https://doi.org/10.26656/fr.2017.4(S6).042

\begin{abstract}
Drying is a process to increase the shelf-life of fruits by decreasing their water content. It is one of the energy consuming processes in food engineering. In many studies, the drying time duration and quality of dried fruits were investigated. In this study, the energy consumption in different drying conditions was investigated for the apple in a laboratory convection dryer. The drying conditions were the application of the temperatures of 40 , 50 , and $60^{\circ} \mathrm{C}$ and the speeds of 0.5 and $1 \mathrm{~ms}^{-1}$ for the drying air using the insulated and non-insulated drying chambers. Independent from drying duration, the highest energy consumption was recorded as $11.2 \mathrm{kWh}$ for the non-insulated dryer under the drying air condition of $40^{\circ} \mathrm{C}$ and $0.5 \mathrm{~ms}^{-1}$. While the lowest energy consumption was only $5.8 \mathrm{kWh}$ for the insulated dryer with the drying air condition of 40 and $50^{\circ} \mathrm{C}$ and the same $0.5 \mathrm{~ms}^{-1}$. The drying duration for these conditions was 537, 313, and 233 mins. To achieve the shortest drying time (153 mins), the condition of $60^{\circ} \mathrm{C}$ and $1 \mathrm{~ms}^{-1}$ in the insulated dryer was used which caused the energy consumption of $7.2 \mathrm{kWh}$.
\end{abstract}

\section{Introduction}

Dehydration of food and agricultural products to increase their shelf life needs a magnitude amount of energy. In most industrialized countries $7-15 \%$ of the total energy consumption of the country refers to food drying processes with almost $25-75 \%$ energy efficiency (Akpinar et al., 2005). In a dryer mechanism, 70\% of costs are from energy consumption. Therefore, to save food drying costs, reduction of energy consumption is an essential effort. It is also linked with environmental issues as most of the energy resources in drying are from fossil fuels (Mujumdar, 2006).

There are some ways to increase energy efficiency in the drying process such as drying air temperature or speed change, use of the small sizes of food, and use of pretreatment processes (for skin thinning and porous creating). Sharifi et al. (2010) searched for orange slide drying models to find conditions with more energy efficiency and less time duration. They measured the highest energy consumption as $335 \mathrm{kWh}$ for $100 \mathrm{~g}$ fresh slices at $40^{\circ} \mathrm{C}$ of drying temperature, where the lowest energy was only $45 \%$ of that $(152 \mathrm{kWh})$ at the temperature of $70^{\circ} \mathrm{C}$. Sadrnia et al. (2014) measured the energy consumption of $1.2 \mathrm{kWh} \mathrm{kg}^{-1}$ for fresh turnip drying at $80^{\circ} \mathrm{C}$ and $3.2 \mathrm{kWh} \mathrm{kg}^{-1}$ (2.7 fold) at $40^{\circ} \mathrm{C}$. The reverse relation between energy consumption and the drying air temperature was also confirmed by Sheidaeipoor Ddizaji (2012). Koyuncu, Tosun and Pinar (2007) measured the drying time duration with a laboratory convective dryer under different drying temperatures. They found that the increasing temperature from 40 to $50^{\circ} \mathrm{C}$, reduces the drying duration by $25 \%$ and to $60^{\circ} \mathrm{C}$ by $36 \%$. They revealed that drying temperature is the most effective factor in drying duration. Sacilik and Elichin (2006) measured less drying time duration in a higher drying air temperature $\left(40\right.$ vs $60^{\circ} \mathrm{C}$ ). However, the upper temperature is limited by quality factors such as colour change as measured by eye or image processing techniques (Seiiedlou Heris, 2010). Koyuncu, Pinar, and Lüle (2007) limited it to less than $70^{\circ} \mathrm{C}$ for Hawthorn drying. Lüle and Koyuncu (2015) found $50^{\circ} \mathrm{C}$ as the best drying temperature for Sorbus fruit by controlling the colour change quality factor.

Abbasi et al. (2012) using an electricity powered dryer, revealed that increasing drying air velocity and temperature increases the energy consumption in corn drying. The highest and lowest energy consumption in their study were 5.3 and $3.6 \mathrm{kWh} \mathrm{kg}^{-1}$ of corn. The lower mass transfer rate from the hard shell of corn in comparison to sliced fruits causes more energy losses by 
increasing air velocity. However, higher enthalpy of the drying air causes drying time duration reduction by increasing mass and heat transfer. According to Sheidaeipoor Dizaji (2012), higher air velocity causes drying time duration reduction, but its effect is less than the high temperature effect. Also, low humidity of the drying air reduces drying duration.

Motevali et al. (2016) expressed the drying energy intensity by measuring the energy consumption per extracted water from chamomile. It was on average 18.9$28.2 \mathrm{MJ} \mathrm{kg}^{-1}$ of water. Therefore, more extracted water (or more water content at the beginning) causes more energy consumption. Obviously, thinner slices of fruits consume less energy in drying as examined by Sacilik and Elichin (2006), Sharifi (2008) and Mohammadi (2011) using 2-9 mm cuts for orange and apple.

Recirculation of exhaust drying air in convective dryers is the other opportunity to improve the drying energy efficiency. The recirculation ratio could be varied along with the drying duration, according to the exergy of drying air measuring several exergy control indices. In the study of Zohrabi et al. (2020), the reduction in overall energy consumption by air recirculation in wood chips drying was measured in the range of $30.7-34.5 \%$.

Another way to increase the efficiency of a dryer is energy loss reduction through dryer walls by insulating. Insulating is used once in while in industrial dryers. However, its effect in energy consumption is not almost mentioned in drying related studies and or their facilities description. Jokiniem and Ahokas (2014) used an insulated dryer for measuring the insulation effect on drying energy consumption. They stated that using an insulated dryer could cause a significant reduction in energy consumption by reducing heat losses through dryer walls which increase food dehydration rate. They revealed over three years the actual energy saving was $16 \%-21 \%$ for the insulated grain dryer compared to its non-insulated counterpart.

According to these studies, almost the effect of drying air temperature on energy consumption is direct, while on the time duration is in a negative trend. But the air velocity effect on energy consumption could be either in negative or positive trends, depends on food material

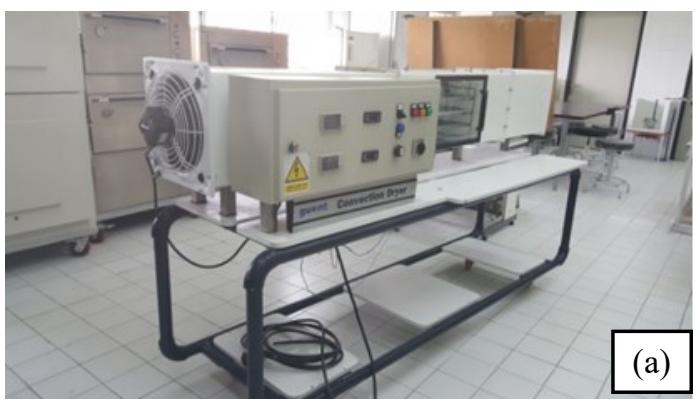

and other drying conditions. Drying indices could also strongly depend on the dryer and food material specifications, cuts, mass, distribution of food materials, and humidity of the drying air which are not the same in studies. These conditions mostly were not described clearly in studies to be able to exactly compare their results.

In this study, the effect of drying air specifications besides the insulation effect on the drying duration and energy consumption were evaluated. Hence, a laboratory convective air dryer for apple slices drying was used described following.

\section{Materials and methods}

As mentioned before, in this study the energy consumption and drying time duration were measured for apple slices drying by a laboratory dryer. The dryer and facilities specifications, measurement devices and drying conditions were as follow:

\subsection{Dryer specifications}

A laboratory dryer was used for the evaluation made at the University of Tabriz for postharvest studies in Biosystems Engineering Department (Figure 1). It was an air convective tunnel dryer with a cross-section of 35 x $35 \mathrm{~cm}^{2}$ and a length of $2.5 \mathrm{~m}$. Both ventilator and heat elements were electrically powered. After them, a vane lattice was located to guide the hot air through the drying chamber. The drying chamber was a four-floor tray located after the heat elements and vanes and hanged from an outer digital weigh with an accuracy of $\pm 0.01 \mathrm{~g}$. The dryer had the facilities to measure and adjust drying air humidity, velocity, and temperature on both sides of the drying chamber.

It was used at first without insulation (Figure 1 a) for half of the experiences and then was covered with foilbacked glass wool insulation with $3 \mathrm{~cm}$ thickness (Figure $1 \mathrm{~b})$ for the other half of experiences.

\subsection{Apple slices}

Fresh golden delicious apple slices with $4 \mathrm{~mm}$ thickness were prepared. For avoiding slices from browning, they were salvaged in a solution of $1 \%$ lemon

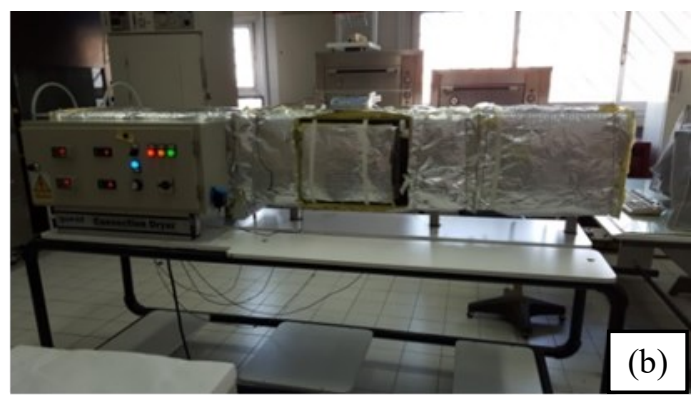

(b)

Figure 1. Air convective tunnel dryer; (a) without insulation and (b) with glass wool insulation 
juice for 5 mins as the only pre-treatment process. In each time of experiences, $100 \mathrm{~g}$ of apple slices were laid on one of the middle floors of the tray. The final moisture content of the dried apples was accepted to be $18 \%$ (wet-based) measured and recorded from the weigh.

\subsection{Experiment's statistical design}

The experiments were under drying air velocity of 0.5 and $1.0 \mathrm{~ms}^{-1}$ and temperature of 40,50 , and $60^{\circ} \mathrm{C}$, where the lab temperature was near $15^{\circ} \mathrm{C}$ with the humidity of less than $30 \%$. Repetition of the same treatments with the insulated dryer and having 3 replications for each condition made it to have a total of 36 experiments. A completely randomized factorial design with three replications was used as the statistical design of the study. The results were analysed with SAS 9.4 statistical software.

\subsection{Measurement devices}

For electric power measurement, an energy (power) analyser (KLEA model) was used with the accuracy of $0.5 \% \mathrm{kWh}$. It was a 3 phase energy analyser as the dryer used 3 phase electricity supply. It could measure the power consumption in drying time duration and record it in its memory to be recalled after each experiment. But during the experiments, regularly every 15 mins the energy consumptions were recorded. Initial energy consumption for stabilizing dryer condition before laying slices in the drying chamber was recorded and subdivided from the total energy consumption in each experiment.

As mentioned before, a $0.01 \mathrm{~g}$ accuracy weigh was used for online measurement of mass losses located on the top of the drying chamber outside which the troy was hanged from. Every 15 mins, the mass reduction of the slices was recorded simultaneously by the energy records. For simple quality control, a fixed camera on a box was used as a colourimeter to take the images which were analysed by Photoshop software to quantify the colour indices, $L, a$, and $b$.

\section{Results and discussion}

As described in the methodology, 36 experiments were conducted in order to find the effects of the drying air temperature, air velocity, and also insulation on the energy and time consumption of apple slices drying. According to the results, the highest energy consumption was recorded as $11.2 \mathrm{kWh}$ for the non-insulated dryer with the drying air condition of $40^{\circ} \mathrm{C}$ and $0.5 \mathrm{~ms}^{-1}$. While the lowest energy consumption was $5.8 \mathrm{kWh}$ for the insulated dryer in both 40 and $50^{\circ} \mathrm{C}$ and with the same $0.5 \mathrm{~ms}^{-1}$ drying air velocity. The drying time duration for the mentioned conditions was 537, 313 and 233 mins, respectively. It means the insulation of the dryer caused up to $48 \%$ reduction in the highest energy consumption by the same drying conditions. In the same way, the drying time duration had a significant reduction $(42-57 \%)$.

The big difference between these values makes the sense that the energy losses through the walls in the noninsulated dryer are very significant. According to the recorded data for energy consumption and time spent in experiments (Table 1), the condition with low temperature, low air velocity and without insulation, takes a very long time (537 mins) in comparison to other conditions. This long operating time consumes a high amount of energy. Because, at first the low enthalpy of this condition takes a long time to dehydrate the slices; second, through this long time a huge amount of energy is lost from the dryer walls and outlet. In other words, retaining more energy inside the insulated dryer causes higher available enthalpy for drying and therefore,

Table 1. Energy consumption and time duration in apple slice drying by air convective tunnel dryer under several drying conditions

\begin{tabular}{|c|c|c|c|c|}
\hline \multicolumn{3}{|c|}{ Dryer conditions } & \multirow[b]{2}{*}{$\begin{array}{l}\text { Time spent } \\
(\min )\end{array}$} & \multirow[b]{2}{*}{$\begin{array}{l}\text { Energy consumption } \\
\qquad(\mathrm{kWh})\end{array}$} \\
\hline $\begin{array}{l}\text { Air temperature } \\
\left({ }^{\circ} \mathrm{C}\right)\end{array}$ & $\begin{array}{l}\text { Air velocity } \\
\left(\mathrm{ms}^{-1}\right)\end{array}$ & $\begin{array}{l}\text { Insulation } \\
\text { (Glass Wool) }\end{array}$ & & \\
\hline 40 & & \multirow{6}{*}{ Without } & 537 & 11.2 \\
\hline 50 & 0.5 & & 265 & 7.8 \\
\hline 60 & \multirow{4}{*}{1} & & 233 & 7.9 \\
\hline 40 & & & 393 & 7.3 \\
\hline 50 & & & 262 & 9.4 \\
\hline 60 & & & 200 & 8.3 \\
\hline 40 & \multirow{4}{*}{0.5} & \multirow{6}{*}{ With } & 313 & 5.8 \\
\hline 50 & & & 233 & 5.8 \\
\hline 60 & & & 183 & 7.4 \\
\hline 40 & & & 350 & 7.7 \\
\hline 50 & \multirow[t]{2}{*}{1} & & 230 & 8.6 \\
\hline 60 & & & 153 & 7.2 \\
\hline
\end{tabular}


reduction in time duration. In cycle wise, reduction in time duration reduces energy losses and energy consumption.

The shortest drying time duration was 153 mins for the condition of $60^{\circ} \mathrm{C}$ and $1 \mathrm{~ms}^{-1}$ in the insulated dryer. It caused the energy consumption of $7.2 \mathrm{kWh}$. Even though the time spent was very short, but the energy consumption was $20 \%$ more than the lowest records. The high velocity and temperature of drying air in this condition caused more energy losses from the air outlet. Also, the increased temperature would cause some more energy losses through the walls.

Overall, according to Table 1, energy consumption and time spent were reduced significantly by using the insulated dryer. But, the choice between different air velocities and temperatures is not clearly easy, as the interaction effects between these two factors are sensible. Statistical variance analysis for these effects on time and energy consumption (made using SAS software) could confirm the significance of these effects.

Table 2 shows the analysis of variance of the effects of the variables on energy consumption in apple slices drying. According to this table, the simple effect of insulation was significant at the significance level of $1 \%$. The simple effects of temperature and velocity were not significant. Despite, double and triple interaction effects of temperature, velocity and insulation were significant (at $1 \%$ level). In this case, the mean value comparison for every single variable makes no sense. As well, for drying time duration the same manner was seen with different levels of these variables.

Table 2. Analysis of the variance of the factors affect the energy consumption by dryer

\begin{tabular}{lccc}
\hline Source of Variation & $\begin{array}{c}\text { Degrees of } \\
\text { Freedom }\end{array}$ & $\begin{array}{c}\text { Mean } \\
\text { Square }\end{array}$ & F-Value \\
\hline Air temperature (T) & 2 & 0.25 & $1.22^{\mathrm{ns}}$ \\
Air velocity (V) & 1 & 1.65 & $8.11^{\mathrm{ns}}$ \\
Insulator (I) & 1 & 21.01 & $103.45^{* *}$ \\
$\mathrm{~T}^{*} \mathrm{~V}$ & 2 & 7.9 & $38.89^{* *}$ \\
$\mathrm{~V}^{*} \mathrm{I}$ & 1 & 10.78 & $53.09^{* *}$ \\
$\mathrm{~T}^{*} \mathrm{I}$ & 2 & 2.15 & $10.61^{\mathrm{ns}}$ \\
$\mathrm{T}^{*} \mathrm{~V}^{*} \mathrm{I}$ & 2 & 8.03 & $39.57^{* *}$ \\
Errors & 24 & 0.2 & - \\
\hline
\end{tabular}

ns: Non-significant, $* *$ significant at $1 \%$ of probability level, respectively

Therefore, it depends on the operator to select the best condition according to desire. If the lowest energy consumption is desired, the condition of $50^{\circ} \mathrm{C}$ and $0.5 \mathrm{~ms}$ ${ }^{-1}$ by using the insulated dryer is the best choice. But if the shortest drying time is desired, implementation of the insulated dryer by $60^{\circ} \mathrm{C}$ and $1 \mathrm{~ms}^{-1}$ drying air would be the best solution. To satisfy both desires, other conditions in the insulated dryer could be chosen by intending the factors such as economic, quality of dried slices, or availability.

The quality of slices was quantified and compared in this study, using the image processing by Photoshop software and analysing $L, a$, and $b$ indices. The only significant difference was from the temperature effect on the redness index $(a)$. In other words, a higher temperature would change the colour of slices to some redness. It could be a reason to use a lower drying temperature. But by simple eye vision, no sensible difference was seen for the dried slices and acceptable colour quality was the same for all slices.

Regardless of the operator desire and dried slices quality, using the insulated dryer causes 21-48\% reduction in energy consumption in comparison to the non-insulated conditions (Table 1). It is in compromise with the reported $16-21 \%$ reduction by Jokiniem and Ahokas (2014) for an actual grain dryer.

By measuring the moisture content of both the inlet and outlet sides of the drying chamber, no significant change was seen. Therefore, the inlet and outlet air moisture differences were ignored for all the conditions. This fact emphasises the other opportunity for energy saving, recirculation of the dryer air. It could be up to $34 \%$ as reported by Zohrabi et al. (2020), but it was not a matter of research in the recent study.

\section{Conclusion}

Drying air temperature and velocity in air convective dryers are the famous factors affecting energy consumption and time duration in a drying process. Higher air temperature and velocity could cause less time spent, but may more energy consumption through air enthalpy losses from the outlet. Insulation of dryer for energy loss reduction through dryer walls was conducted in this research besides testing varying temperature and velocity effects. These factors were affecting energy consumption and time duration significantly. The results showed $21-48 \%$ reduction in the energy consumption for the insulated dryer, depending on the drying conditions. The lower time spent was not achievable simultaneously with the lowest energy consumption. To decide between shorter drying time and higher energy saving, different levels of air temperature and velocity could be used according to the desires of the operator. Quality colourimeter factors showed that the higher temperatures would cause some increase in the red index $(a)$ for apple slices. Despite, higher temperature beside higher air velocity in the insulated dryer makes drying time duration much shorter, up to $28 \%$ of the longest drying time. 


\section{Conflict of interest}

The authors declare no conflict of interest.

\section{Acknowledgment}

The research work was funded by University of Tabriz, granting by regular MSc. program.

\section{References}

Abbasi, S., Minaei, S. and Khoshtaghaza, M.H. (2012). Investigation of dry kinetics of intensity and energy consumption of Maize thin layer. Journal of Agricultural Machinery, 4(1), 98-107. [In Persian].

Akpinar, E.K., Midili, A. and Bicer, Y. (2005). Energy and exergy of potato drying process via cyclone type dryer. Energy Conversion and Management, 46, 2350-2552. https://doi.org/10.1016/ j.enconman.2004.12.008

Jokiniem, T.H. and Ahokas, J.M. (2014). Effect of heat insulation on the energy consumption of recirculating mixed-flow batch grain dryer. Agricultural Engineering International: CIGR Journal, 16(3), 205-213.

Koyuncu, N., Pinar, Y. and Lüle, F. (2007). Convective drying characteristics of azarole red (Crataegus monogyna Jacq) and yellow (Crataegus aronia Bose) fruits. Journal of Food Engineering, 78(4), 1471-1475. j.jfoodeng.2005.09.036

Koyuncu, T., Tosun, I. and Pinar, Y. (2007). Drying characteristics and heat energy requirement of cornelian cherry fruits. Journal of Food Engineering, 78(2), 735-739. https://doi.org/10.1016/ j.jfoodeng.2005.09.035

Lüle, F. and Koyuncu, T. (2015). Convective and microwave drying characteristics of Sorbus fruits (Sorbus domestical). Procedia Social and Behavioural Sciences, 195, 2634-2643. https:// doi.org/10.1016/j.sbspro.2015.06.467

Mohammadi, A. (2011). Choosing the right Kiwi drying model of Hayward cultivar and comparing the time and amount of energy consumed. Iran: University of Tehran, MSc. Thesis. [In Persian].

Motevali, A., Minaei, S., Banakar, A. and Ghobadian, B. (2014). Energy analyses and drying kinetics of chamomile leaves in microwave-convective dyer. Journal of the Saudi Society of Agricultural Sciences, 15(2), 179-187. https://doi.org/10.1016/ j.jssas.2014.11.003

Mujumdar, A. (2006). Handbook of industrial drying, $3^{\text {rd }}$ ed. USA: Taylor and Francis Group, LLC.

Sacilik, K. and Elicin, A.K. (2006). The thin layer drying characteristics of organic apple slices. Journal of Food Engineering, 73(3), 281-289. https:// doi.org/10.1016/j.jfoodeng.2005.03.024

Sadrnia, H., Monfared, H. and Khojastepoor, M. (2014). Comparison of two drying methods on energy consumption of qualitative parameters of turnip purple top white globe. Journal of Agricultural Machinery, 5(1), 143-153. [In Persian].

Seiiedlou Heris, S. (2010). Experimental study and mathematical simulation of drying process in convectional air-dried apples. Iran: University of Tabriz, PhD Thesis. [In Persian].

Sharifi, M. (2008). Evaluation of drying models and comparison of time and energy consumption under disturbed drying conditions of Thompson orange leaf. Iran: University of Tehran, MSc. Thesis. [In Persian].

Sharifi, M., Rafiee, S., Keyhani, A.R. and Omid, M. (2010). Effects of drying conditions of sliced orange on energy consumption. Iranian Journal of Food Science and Technology, 7(3), 109-116. [In Persian].

Sheidaeipoor Dizaji, A. (2012). Energy- exergy analyses in convectional drying process of pre-treated potato slices by ultrasonic waves. Iran: University of Tabriz, MSc. Thesis. [In Persian].

Zohrabi, S., Aghbashlo, M., Seiiedlou, S.S., Scaar, H. and Mellmann, J. (2020). Energy saving in a convective dryer by using novel real-time exergybased control schemes adjusting exhaust air recirculation. Journal of Cleaner Production, 257, 122. https://doi.org/10.1016/j.jclepro.2020.120394 